\title{
Position Control of 3-DOF Articulated Robot Arm using PID Controller
}

\author{
War War Naing \\ Department of Mechatronic \\ Engineering \\ Technological University \\ Thanlyin, Myanmar
}

\author{
Kyi Zar Aung \\ Department of Mechatronic \\ Engineering \\ Technological University \\ Thanlyin, Myanmar
}

\author{
Aung Thike \\ Department of Mechatronic \\ Engineering \\ Technological University \\ Thanlyin,Myanmar
}

\begin{abstract}
The purpose of this paper is to eliminate the manual control for pick and place system. The robot arm is designed with three joints, two links and three Dc motors. Arduino microcontroller is used to generate the required angular position of the robot joints. In this research, the link length of the robot arm is calculated to enable carrying the desire object weight. The position of the robot arm end effector is calculated with kinematic modeling method which include forward and inverse kinematic. Robotic tool box is used to task the position of the robot arm using forward and inverse kinematic. PID control method is used for accurate position of the end effector. In this research the gain of the PID controller is tuned by using the Ziegler-Nichol method. In this research, Output position of the robot arm are shown in MATLAB simulation. Forward and inverse kinematics result also are shown in MATLAB GUI.
\end{abstract}

Keywords: ARDUINO microcontroller, DC motors, Kinematic modeling, robot arm, PID controller, GUI

\section{INTRODUCTION}

An industrial manipulator is basically a mechanical arm operating under computer control, in other word a robot arm. Robots are modeled as rigid bodies (Links) and joints. The joints are assumed to induce either pure rotation or translation motion. These links and joints make up kinematic chains which form the basic structure of the equipment. In a production line like injection molding, stamping, assembly, packaging, etc. (i.e. point to point (PTP) application), or in specialized machine operations like welding, cutting, grinding, etc. (i.e. continuous path robots)[1].

Kinematics is the science of geometry in motion. It is restricted to a pure geometrical description of motion by means of position, orientation, and their time derivatives. The Denavit Hartenberg notation gives a standard methodology to write the kinematic equations of a manipulator. There are two important aspects in kinematic analysis of robots: the Forward Kinematics problem and the Inverse Kinematics problem. Forward kinematics refers to the use of the kinematic equations of a robot to compute the position of the endeffector from specified values for the joint parameters. Inverse kinematics refers to the use of the kinematics equations of a robot to determine the joint parameters that provide a desired position of the end-effector [2].

Robotic Arm controller is the challenging and demanding activity in industrial field as well as military and other applications. Robots are generally used to do unsafe, dangerous, highly repetitive, and unpleasant tasks which have many different functions such as material handling, assembly, arc welding, resistance welding, machines tool load and unload functions, painting, spraying, etc. A robotic arm is a Robotic Arm controller is the challenging and demanding activity in industrial field as well as military and other applications. A robotic arm is a robot manipulator, normally programmable with analogous functions to a human arm. Usually robots are set up for a task by the teach-and-repeat technique [3].
PID controller is a single loop controller which was introduced in 1940. PID controllers have been extensively used in industrial applications. The success of PID controllers is due to their simple structure and easiness of setting their parameters (Proportional - Integrative - Derivative[4].

This paper has three main contributions. Firstly, mechanical design of the robot arm is considered to pick up the desired object. Secondly, forward and inverse kinematic are described using the robotic tool box in MATLAB software. Finally, PID gain has been designed for the system using manual PID tuning by using Ziegler Nichol Method. This paper has been organized as follows, Section-II describes the mechanical design of 3_DOF(Degree of freedom) Articulated Robot Arm. Section-III calculates the kinematic modelling. Section-IV expresses tuning the PID gain for DC motor. Section V shows simulation results for 3-DOF Articulated robot arm with MATLAB/Simulink.

\section{PROCESS FLOW CHART OF ROBOT ARM CONTROL}

All In this research, the design parameters of the robot arm are considered. And then, the position of the end effector is calculated with kinematic modeling method in PC. To get the actual position of the robot joint angle, PID controller is used. In this paper, Kinematic modeling is an essential role in design and robot arm control. Robot arm kinematics deals with the analytical study of geometry motion of robot arm from fixed reference of coordinate system as a function of time without regard to movements that causes the motion. 
International Journal of Science and Engineering Applications

Volume 7-Issue 09,254-259, 2018, ISSN:-2319-7560

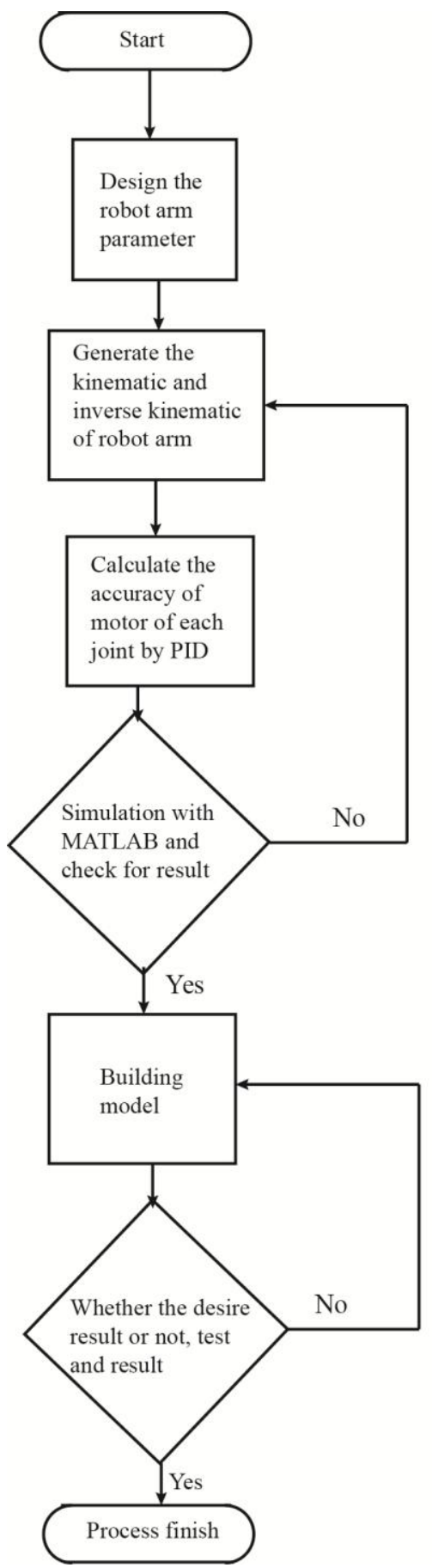

Figure 1. Flow chart of the robot arm system

\section{DESIGN OF 3-DOF ARTICULATED ROBOT ARM}

All in this research, the design of the system is shown in fig.1. In this design, there are two conveyors and robot arm. Conveyor 2 carries the objects and conveyor 1 carries the packages. Robot arm performs picking and placing the objects. The design of robot arm is 3-DOF articulated robot arm and consist of three joints. Joint 1 is base. Joint 2 and joint 3 are elbow and shoulder respectively.

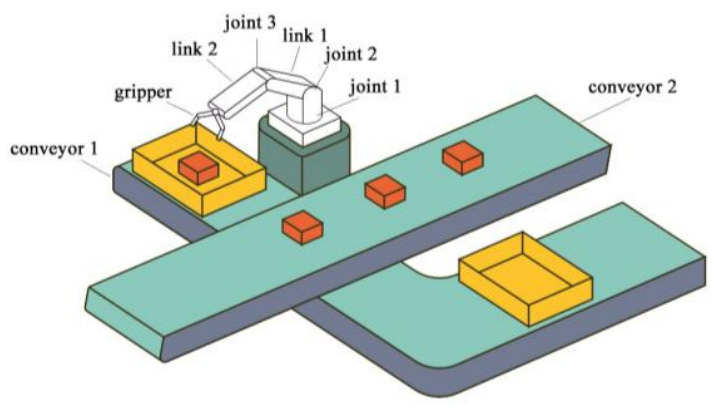

Figure 2. Design of the system

Table 1 shows the motor specifications for each motor in robot arm. In this table 70:1 means the gear ratio of output shaft and inner rotor. Three motors are different in weight because require torques are differed. Motor cap means that it is mounted on the shaft. Table 2 shows the material specification for 3-DOF articulated robot.

Table 1. Motor specifications of each joint

\begin{tabular}{|c|c|c|}
\hline Type & Weight & Torque \\
\hline $70: 1$ Metal gear motor & $225 \mathrm{~g}$ & $14 \mathrm{~kg}-\mathrm{cm}$ \\
\hline $75: 1$ Metal gear motor & $104 \mathrm{~g}$ & $17 \mathrm{~kg}-\mathrm{cm}$ \\
\hline 19:1 Metal gear motor & $215 \mathrm{~g}$ & $6.04 \mathrm{~kg}-\mathrm{cm}$ \\
\hline Motor cap & $6.8 \mathrm{~g}$ & --------- \\
\hline
\end{tabular}

Table 2. Material specification

\begin{tabular}{|c|c|c|c|c|c|}
\hline Material & Density & $\mathbf{L}_{\mathbf{1}}$ & $\mathbf{L}_{\mathbf{2}}$ & Width & Thickness \\
\hline Acrylic & $\begin{array}{c}0.00118 \\
\left(\mathrm{~kg} / \mathrm{cm}^{\wedge} 3\right)\end{array}$ & $\begin{array}{c}16 \\
(\mathrm{~cm})\end{array}$ & $\begin{array}{c}15 \\
(\mathrm{~cm})\end{array}$ & $\begin{array}{c}3 \\
(\mathrm{~cm})\end{array}$ & $\begin{array}{c}1 \\
(\mathrm{~cm})\end{array}$ \\
\hline
\end{tabular}

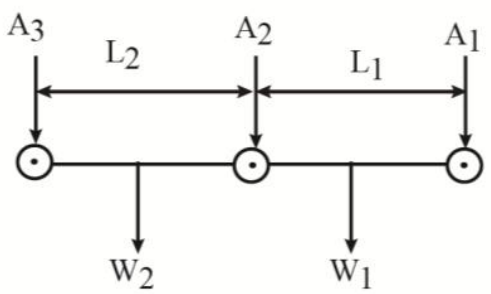

Figure 3. Free body diagram of the robot arm

$$
\begin{aligned}
& \mathrm{T}_{2}=0.48036 \mathrm{~N}-\mathrm{m} \\
& \mathrm{T}_{1}=1.2633 \mathrm{~N}-\mathrm{m}
\end{aligned}
$$




\subsection{Calculate the Kinematic Modelling}

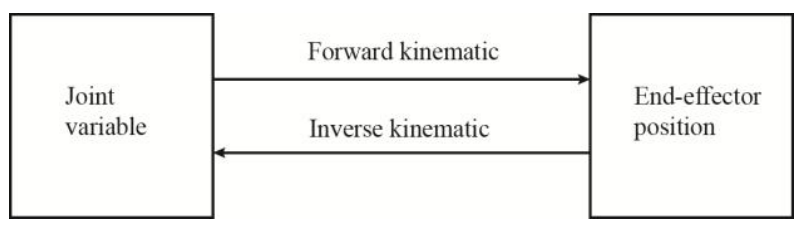

Figure 4. Kinematic block diagram of robot arm.

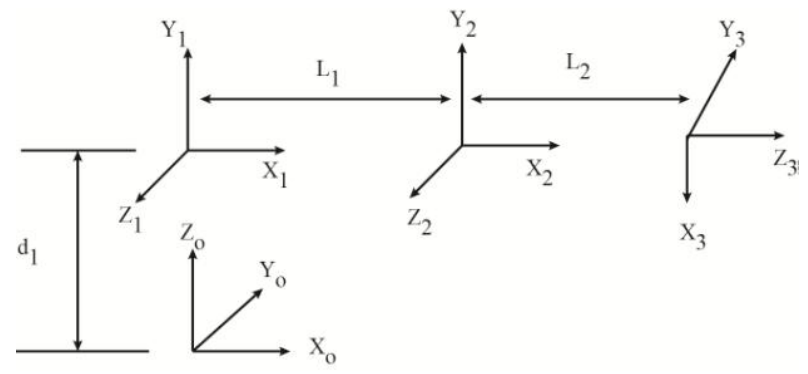

Figure 5. Kinematic Frame of 3-DOF robot arm

Table 3. D-H Parameters for robot arm

\begin{tabular}{|c|c|c|c|c|}
\hline $\mathbf{I}$ & $\mathbf{a}_{\mathbf{i}}$ & $\mathbf{d}_{\mathbf{i}}$ & $\boldsymbol{\alpha}_{\mathbf{i}}$ & $\boldsymbol{\theta}_{\mathbf{i}}$ \\
\hline 1 & 0 & 5 & 90 & $\theta_{1}$ \\
\hline 2 & 13 & 0 & 0 & $\theta_{2}$ \\
\hline 3 & 9 & 0 & 0 & $\theta_{3}$ \\
\hline
\end{tabular}

Transformation matrix for robot arm

$$
\mathrm{T}_{\mathrm{i}}^{\mathrm{i}-1}=\left[\begin{array}{cccc}
\mathrm{c} \alpha_{\mathrm{i}} & -\mathrm{c} \alpha_{\mathrm{i}} \mathrm{s} \theta_{\mathrm{i}} & \mathrm{s} \alpha_{\mathrm{i}} \mathrm{s} \theta_{\mathrm{i}} & \mathrm{a}_{\mathrm{i}} \mathrm{c} \theta_{\mathrm{i}} \\
\mathrm{s} \theta_{\mathrm{i}} & \mathrm{c} \alpha_{\mathrm{i}} \mathrm{c} \theta_{\mathrm{i}} & -\mathrm{s} \alpha_{\mathrm{i}} \mathrm{s} \theta_{\mathrm{i}} & \mathrm{a}_{\mathrm{i}} \mathrm{s} \theta_{\mathrm{i}} \\
0 & \mathrm{c} \alpha_{\mathrm{i}} & \mathrm{c} \alpha_{\mathrm{i}} & \mathrm{d}_{\mathrm{i}} \\
0 & 0 & 0 & 1
\end{array}\right]
$$

\subsection{Forward Kinematics Analysis}

Forward kinematics usually refers to home position of geometric link parameters and used to find the position and orientation of end effectors. For the research work, 3-DOF robotic arm was selected. It is a vertical articulated robot, with three revolute joints. It has a stationary base, shoulder and elbow. Fig. 1 is a simple block diagram which indicates the relationship between direct and inverse kinematics problem. Fig.3 indicates robots arm links and the coordinate frame assignment.

$$
\begin{aligned}
& \mathrm{P}_{\mathrm{x}}=\mathrm{L}_{2} \mathrm{C}_{2} \mathrm{C}_{1} \mathrm{C} \theta_{3}-\mathrm{L}_{2} \mathrm{C}_{1} \mathrm{~S} \theta_{3} \mathrm{~S} \theta_{2}+\mathrm{L}_{1} \mathrm{C} \theta_{1} \mathrm{C} \theta_{2} \\
& \mathrm{P}_{\mathrm{y}}=\mathrm{L}_{2} \mathrm{C} \theta_{2} \mathrm{~S} \theta_{1} \mathrm{C} \theta_{3}-\mathrm{L}_{2} \mathrm{~S} \theta_{2} \mathrm{~S} \theta_{1} \mathrm{~S} \theta_{3}+\mathrm{L}_{1} \mathrm{~S} \theta_{1} \mathrm{C} \theta_{2} \\
& \mathrm{P}_{\mathrm{Z}}=-\mathrm{L}_{2} \mathrm{~S} \theta_{2} \mathrm{C}_{3}-\mathrm{L}_{2} \mathrm{~S}_{3} \mathrm{C}_{2}-\mathrm{L}_{1} \mathrm{~S} \theta_{2}+\mathrm{d}_{1}
\end{aligned}
$$

Where, $\mathrm{S} \theta=\sin \theta$ and $\mathrm{C} \theta=\cos \theta$

\subsection{Inverse Kinematics Analysis}

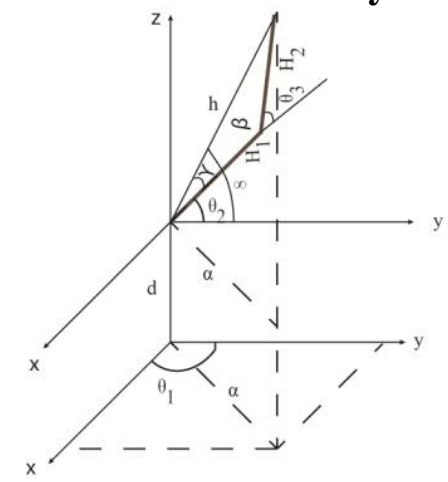

Figure 6. Isometric view of the robot arm

Inverse kinematics usually refers to position and orientation of end effectors. It helps to find joint variables to achieve correct position of source location part .The orientation can be calculated with the given position into one homogeneous transformation matrix $(\mathrm{T})$ that describes the orientation and position of the end effector, and then the inverse kinematics is applied to determine each joint angle. Three are three solution approaches; analytical, numerical and semi analytical [11].In this paper, analytical method is used.

$$
\begin{aligned}
& \theta_{1}=\tan ^{-1} \frac{\mathrm{y}}{\mathrm{x}} \\
& \theta_{3}=180-\beta \\
& \theta_{2}=\tan ^{-1} \frac{\mathrm{z}}{\mathrm{a}}-\sin ^{-1} \frac{\mathrm{H}_{2} \cdot \sin \beta}{\mathrm{h}}
\end{aligned}
$$

\section{TUNING THE PID GAIN FOR DC MOTOR}

In the system, power supply of robot arm control system is used the 12V DC supply for all DC motors and arduino microcontroller.

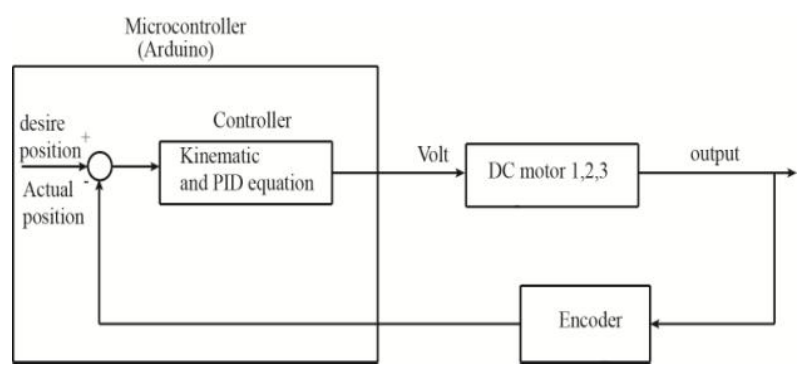

Figure 7. Control block diagram of robot arm control

In this system, DC Motors have six wires. Red colour is motor power (connect to one motor terminal). Black colour is also motor power (connects to the other motor terminal). Green colour is encoder GND. Blue colour is encoder Vcc (3.5$20 \mathrm{~V})$. Yellow colour is encoderA output and White colour is encoderB output. Most DC motors run at the highest RPM (revolutions per minute) when the required power is supplied. The speed of DC motors is controlled by using pulse width modulation (PWM), a technique of rapidly pulsing the power on and off. The percentage of time spent cycling the on/off ratio determines the speed of the motor. Each pulse is so rapid 
that the motor appears to be continuously spinning with no stuttering.

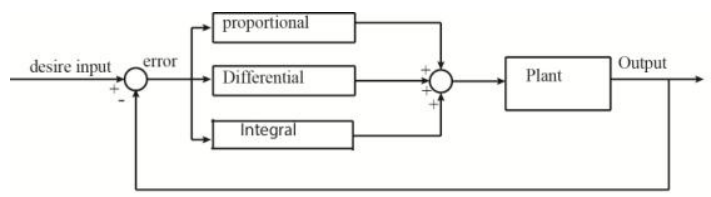

Figure 8. Block diagram of PID Controller

PID is a classic way of automatic control theory and the general trial control mode. Position can be controlled by PID controller. A PID controller supplies a control signal that has a component proportional to the tracking error of a system, a component proportional to the accumulation of this error over time and a component proportional to the time rate of change of this error. This module will cover these different components and some of their different combinations that can be used for control purposes. In engineering applications, the controllers appear in many different forms: as a stand-alone controller, as part of hierarchical, distributed control systems, which was built into embedded components. A proportionalintegral- derivative controller (PID controller) is widely used in industrial control systems. It is a generic feedback control loop mechanism and used as feedback controller. PID loop defines how much energy is to be fed to the motor at any instant during a move. This is based on where the motor is and where it was expected to be. There are four parts in the equation and this determines the load in which three main components are referred to as the P, I, D and the minor friction component is referred to as $\mathrm{K}$.

$\mathrm{P}$ determines the reaction to current error, I determines reaction to the sum of recently appeared errors, and D determines reaction according to the rate off error changing. The sum of all three parts contribute the control mechanism such as speed control of a motor in which $\mathrm{P}$ value depends upon current error, I also depends on the accumulation of previous error and D predicts future error based on the current rate of change.

Table 4. Manual P,I and D Parameters tuning

\begin{tabular}{|c|c|c|c|c|c|}
\hline Gain & $\begin{array}{c}\text { Rise } \\
\text { time }\end{array}$ & $\begin{array}{c}\text { Oversho } \\
\text { ot }\end{array}$ & $\begin{array}{c}\text { Settlin } \\
\text { g time }\end{array}$ & $\begin{array}{c}\text { Stea } \\
\text { dy } \\
\text { state } \\
\text { error }\end{array}$ & $\begin{array}{c}\text { Stabili } \\
\text { ty }\end{array}$ \\
\hline $\begin{array}{c}\text { Incre } \\
\text { asing } \\
\text { Kp }\end{array}$ & $\begin{array}{c}\text { Decr } \\
\text { ease }\end{array}$ & Increase & $\begin{array}{c}\text { Small } \\
\text { Increas } \\
\mathrm{e}\end{array}$ & $\begin{array}{c}\text { Decr } \\
\text { ease }\end{array}$ & $\begin{array}{c}\text { Degrad } \\
\mathrm{e}\end{array}$ \\
\hline $\begin{array}{c}\text { Incre } \\
\text { asing } \\
\text { Ki }\end{array}$ & $\begin{array}{c}\text { Small } \\
\text { Decr } \\
\text { ease }\end{array}$ & Increase & $\begin{array}{c}\text { Increas } \\
\text { e }\end{array}$ & $\begin{array}{c}\text { Large } \\
\text { Decr } \\
\text { ease }\end{array}$ & $\begin{array}{c}\text { Degrad } \\
\text { e }\end{array}$ \\
\hline $\begin{array}{c}\text { Incre } \\
\text { asing } \\
\text { Kd }\end{array}$ & $\begin{array}{c}\text { Small } \\
\text { Decr } \\
\text { ease }\end{array}$ & Decrease & $\begin{array}{c}\text { Decrea } \\
\text { se }\end{array}$ & $\begin{array}{c}\text { Mino } \\
\mathrm{r} \\
\text { Chan } \\
\text { ge }\end{array}$ & Improv \\
e
\end{tabular}

$\mathrm{U}_{\mathrm{p}}(\mathrm{t})=\mathrm{K}_{\mathrm{p}} \cdot \mathrm{e}(\mathrm{t})$

$$
\begin{aligned}
& U_{I}(t)=K_{I} \int_{0}^{t} e(t) d t \\
& U_{D}(t)=K_{D} \frac{d}{d t} \cdot e(t) \\
& U(t)=K_{p} \cdot e(t)+K_{I} \int_{0}^{t} e(t) d t+K_{D} \frac{d}{d t} e(t)
\end{aligned}
$$

Table 5. Ziegler-Nichols tuning rule based on critical gain $\mathrm{K}_{\mathrm{cr}}$ and critical period $\mathrm{P}_{\mathrm{cr}}$ (second method).

\begin{tabular}{|c|c|c|c|}
\hline $\begin{array}{c}\text { Type of } \\
\text { controller }\end{array}$ & $\mathbf{K}_{\mathbf{P}}$ & $\mathbf{T}_{\mathbf{i}}$ & $\mathbf{T}_{\mathbf{d}}$ \\
\hline $\mathrm{P}$ & $0.5 \mathrm{~K}_{\mathrm{cr}}$ & $\infty$ & 0 \\
\hline $\mathrm{PI}$ & $0.45 \mathrm{~K}_{\mathrm{cr}}$ & $1 / 1.2 \mathrm{P}_{\mathrm{cr}}$ & 0 \\
\hline $\mathrm{PID}$ & $0.6 \mathrm{~K}_{\mathrm{cr}}$ & $0.5 \mathrm{P}_{\mathrm{cr}}$ & $0.125 \mathrm{P}_{\mathrm{cr}}$ \\
\hline
\end{tabular}

$\mathrm{G}_{\mathrm{c}}(\mathrm{s})=\mathrm{K}_{\mathrm{p}}\left(1+\frac{1}{\mathrm{~T}_{\mathrm{i}} \mathrm{s}}+\mathrm{T}_{\mathrm{d}} \mathrm{s}\right)$

\section{GRAPHICAL USER INTERFACE (GUI)}

Graphical User Interface development environment offers a set of tools in order to generate graphical user interface (GUI) [11].They greatly facilitate the operation of designing and building GUIs. A GUI example has been prepared for $3 \mathrm{DOF}$ Robot including the forward kinematics. GUI is given in the following figures. Push buttons, sliders, axes etc. can be added on it. Additions are being visible on the $\mathrm{m}$. file simultaneously as a function .Robotics Toolbox is embedded in to GUI. The results are compared with the expressions obtained in the analytical solution. It is proved that same results are obtained by the robotic toolbox and the analytical solution.

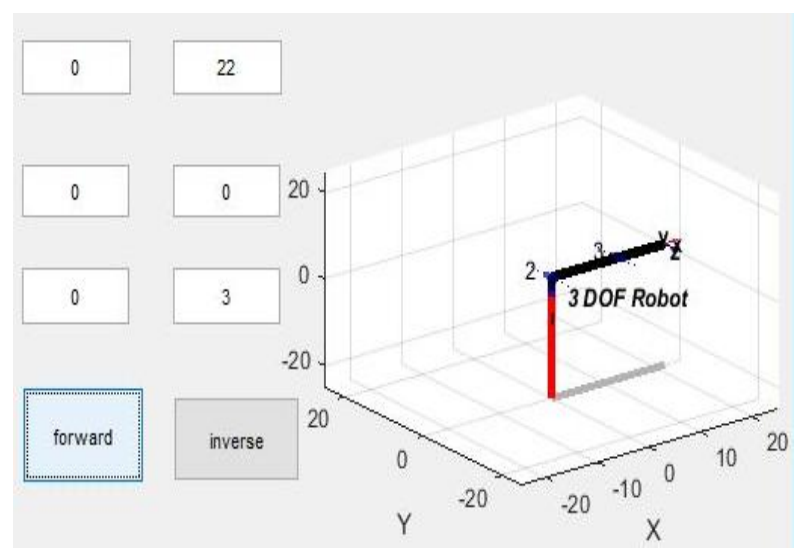

Figure 9. GUI window for robot arm

Figure 9. Shows the designed simulation program by MATLAB/GUIDE to create serial link robot (Link 1-3 ) and 
control the joint angles $\left(\mathrm{q}_{1}, \mathrm{q}_{2}, \mathrm{q}_{3}\right)$. DH parameters can directly be changed .Figure 9 shows the home position of the robot and the path generated with the given coordinates, respectively.

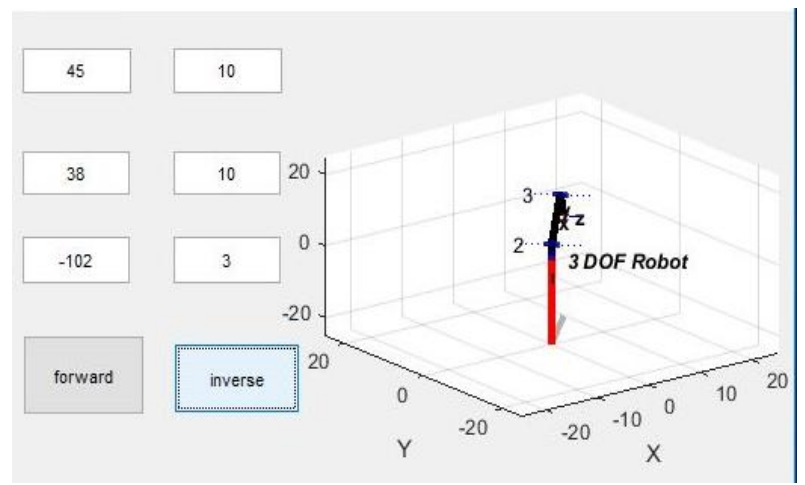

Figure 10. The robot arm position when $\mathrm{x}=10, \mathrm{y}=10$ and $\mathrm{z}=3$

\section{EXPERIMENTAL TEST AND \\ RESULTS}

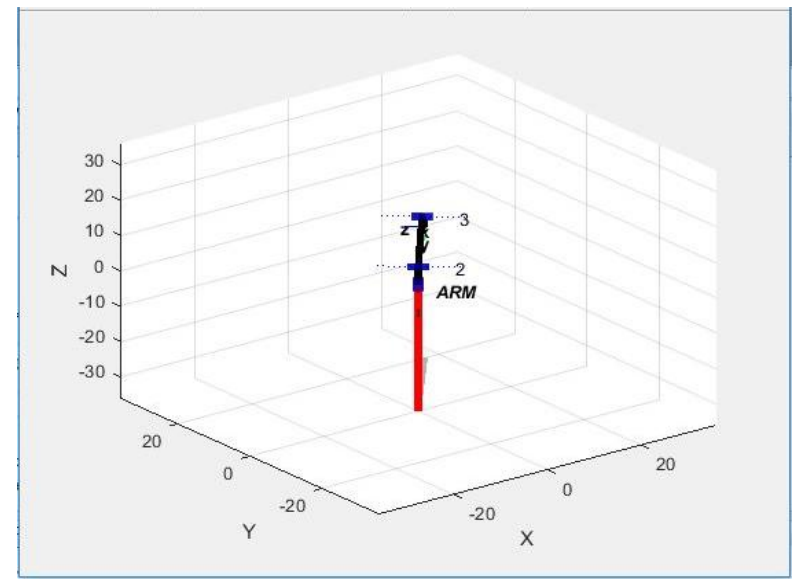

Figure 11. The robot arm position when $\theta 1=55^{\circ}, \theta 2=25^{\circ}$ and $\theta 3=66^{\circ}$

The transformation matric is following.

$\begin{array}{rrrr}0.4924 & -0.4132 & -0.7660 & 17.0504 \\ 0.4924 & -0.4132 & 0.6428 & 20.3199 \\ -0.6428 & -0.7660 & 0.0000 & 0.8305 \\ 0 & 0 & 0 & 1.0000\end{array}$

Therefore, from the matric, the position of end effector is $\mathrm{X}=17.0504 \mathrm{~cm}, \mathrm{Y}=20.3199 \mathrm{~cm}$ and $\mathrm{Z}=0.8305$.

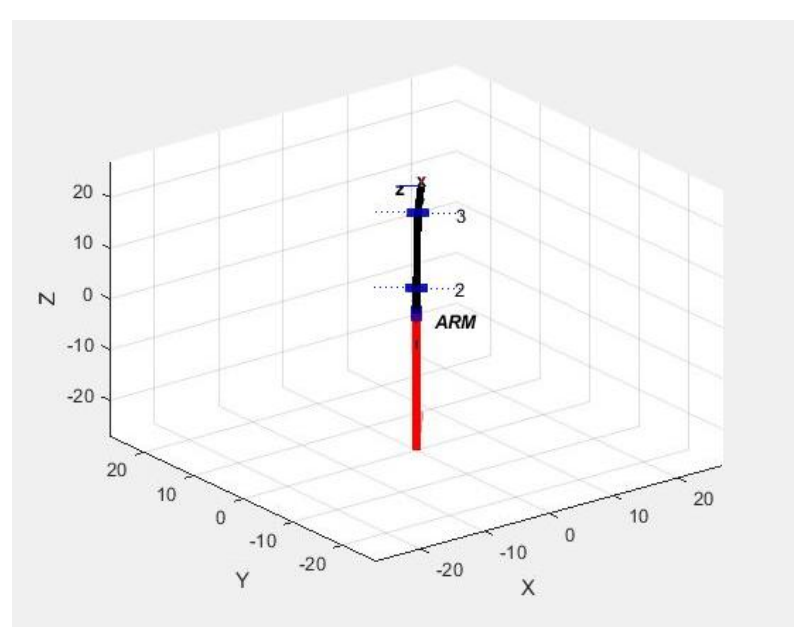

Figure 10. The robot arm position when $\theta 1=50^{\circ}, \theta 2=-75^{\circ}$ and $\theta 3=70^{\circ}$

The transformation matric is following

$\begin{array}{rrrc}0.6428 & 0.0000 & -0.7660 & 8.6431 \\ 0.7660 & 0.0000 & 0.6428 & 10.3004 \\ 0 & -1.0000 & 0.0000 & 17.2160 \\ 0 & 0 & 0 & 1.0000\end{array}$

Therefore, from the matric, the position of end effector is $\mathrm{X}=8.6431 \mathrm{~cm}, \mathrm{Y}=10.3004 \mathrm{~cm}$ and $\mathrm{Z}=17.2160$.

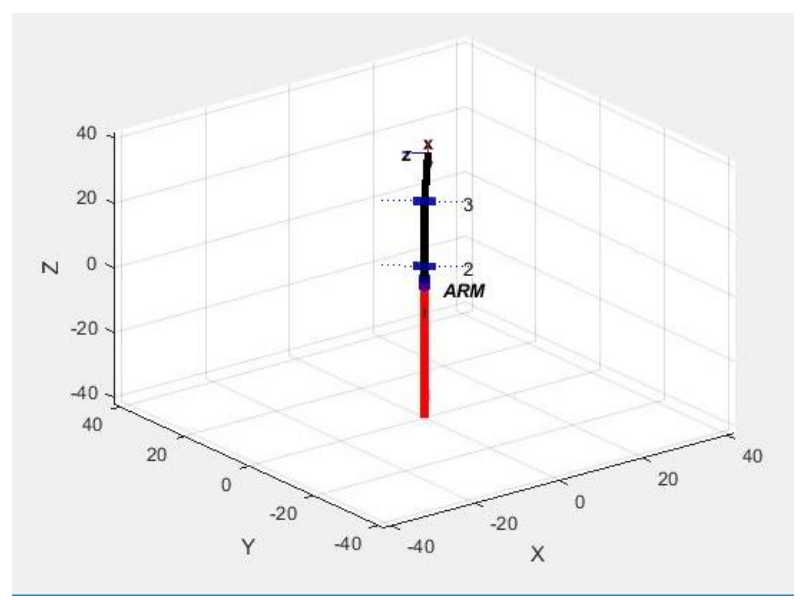

Figure 11. The robot arm position when $\theta 1=50^{\circ}, \theta 2=-75^{\circ}$ and $\theta 3=70^{\circ}$

The transformation matric is following

$\begin{array}{rrrc}0.6040 & 0.2198 & -0.7660 & 10.2684 \\ 0.7198 & 0.2620 & 0.6428 & 12.2374 \\ 0.3420 & -0.9397 & 0.0000 & 30.8143 \\ 0 & 0 & 0 & 1.0000\end{array}$

Therefore, from the matric, the position of end effector is $\mathrm{X}=10.2684 \mathrm{~cm}, \mathrm{Y}=12.2374 \mathrm{~cm}$ and $\mathrm{Z}=30.8143$. 


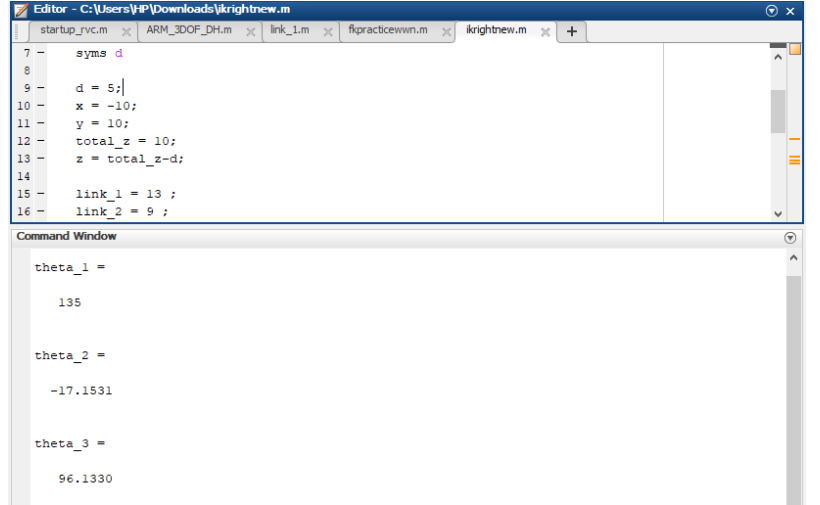

Figure 12. The robot arm position with inverse kinematic

From Fig.12, when the robot arm position is $X=-10, Y=10$ and $Z=10$, the joint angles are $\theta 1=135^{\circ}, \theta 2=-17.1531^{\circ}$ and $\theta 3=96.1330^{\circ}$

The following results are tuning the PID gain for each DC gear motor.

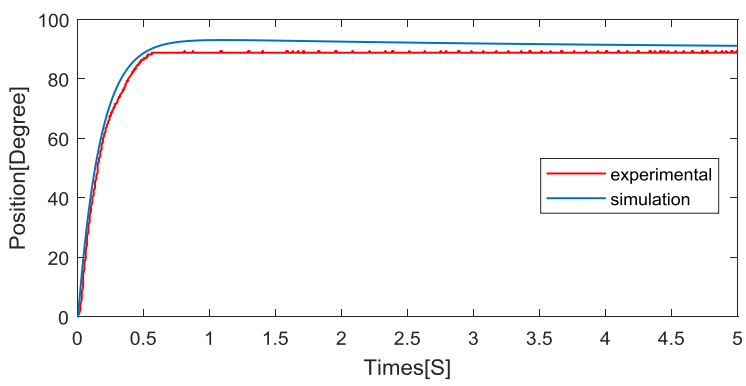

Figure 13. The combinatin of simulation and experimental for 19:1 metal gear motor with the gain is $\mathrm{Kp}=1.14, \mathrm{Ki}=0.2923$, $\mathrm{Kd}=0.185$ with desire angle is $90^{\circ}$.

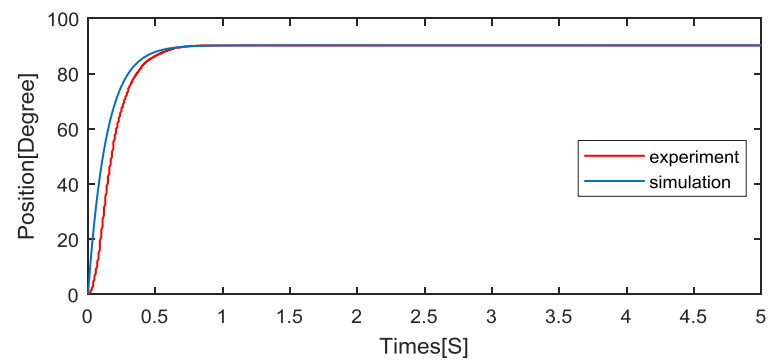

Figure 14. The combinatin of simulation and experimental for $70: 1$ metal gear motor with the gain is $\mathrm{Kp}=4.14, \mathrm{Ki}=0.075$, $\mathrm{Kd}=0.056$ with desire angle is $90^{\circ}$.

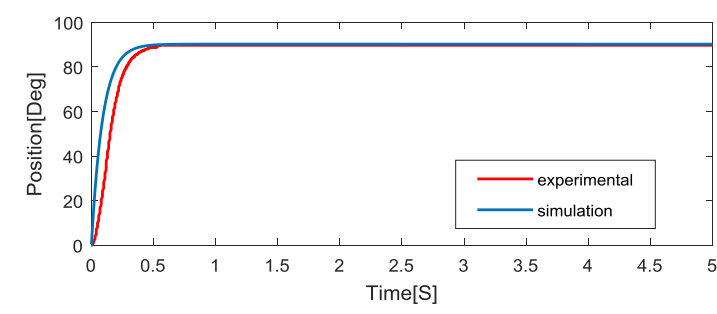

Figure 15. 75:1 metal gear motor with the gain is $\mathrm{Kp}=5.28$, $\mathrm{Ki}=0.144, \mathrm{Kd}=0.4818$ with desire angle is $90^{\circ}$.

\section{DISCUSSION AND CONCLUSION}

This paper has been researched the position control for $3 \mathrm{DOF}$ articulated robot arm. The link length and weight of the robot arm are considered by using required parameters. The forward and inverse kinematic are calculated by using D-H parameters and analytical method. And then, PID controller is used to get the actual position of robot arm. PID gains are tuned by using Ziegler Nichol method. Finally, the results are shown in MATLAB Simulink software.

\section{ACKNOWLEDGMENTS}

The author is very thankful to Dr.Theingi, Rector of Technological University Thanlyin, for her encouragement, invaluable permission and her kind support in carrying out this paper work. The author is deeply grateful to all the teachers from Department of Mechatronic Engineering, Technological University(Thanlyin), for their support, encouragement and invaluable guidance in preparation of this research. The author would like to express their thanks to all persons who have given support during the preparation period of this research work.

\section{REFERENCES}

[1] Umar Abubakar, Wang Zhongmin and Gao Ying.2014."Kinematic Analysis and Simulation of a 6DOF Industrial Manipulator". International Journal of science and Research(IJSR), volume 3.

[2] Daniel Constantin, Marin Lupoae, Catalin Baciu and Dan-Ilie Buliga,2013,ISBN: 978-1-61804-288-0.

[3] Asnor Juraiza Ishak, Azura Che Soh and Mohamad Asmi Ashaari.2013."Positin Control of Arm Mechanism Using PID Controller"vol.47 No2, Journal of Theoretical Applied Information Technology.

[4] N.G. ADAR and R.Kozan,2016. "Comparsion between Real Time PID and 2-DOF PID Controller for 6-DOF Robot Arm". Vol130,No 1,Special issue of the $2^{\text {nd }}$ International Conference on Computational and Experimental Science and Engineering(ICCESEN )

[5] J.Lin and Z.-Z Huang,2006, "Tuning the PID Parameters for Robot Manipulators With Compliant Bases By Using Grey Theory", Proceeding of the 2006 IEEE International Conference on Control Applications Munich, Germany.

[6] Vivek Deshpande and P M George, " Kinematic Modelling and Analysis of 5 DOF Robotic Arm" vol 4,No 2, International Journal of Robotics Research and Development(IJRRD) ISSN(P): 22501592;ISSN(E):2278-9421.

[7] Suyash Shrivastava and Eklavya Gupta,2017,"'Forward Kinematics of Articulated Robotic Arm"vol.6 No8. International Journal of Research and Scientific Innovation(IJRSI).

[8] Ms. Vaijayanti B. and PG. 2017.” Robotic Arm Control Using Pid Controller and Inverse Kinematics" vol5,No 2. International Journal of Engineering Development and Research

[9] Mehment Erkan Kutuk, Memik Taylan DAS and Lale Canan Dulger. 2017," Forward and Inverse Kinematics Analysis of Denso Robot" Proceedings of the International Symposium of Mechanism and Machine Science. 
International Journal of Science and Engineering Applications

Volume 7-Issue 09,254-259, 2018, ISSN:-2319-7560

[10] H.Ferdinando, H.Wicaksono and R.Wibowo, 2017," The Implementation of PID Controller in the Pick and Place Robot".Proceeding of the International Symposium of Mechanism and Machine Science.

[11] S.Kucuk and H.Bingul, 2016. "The Inverse Kinematic Solution of Industrial robot manipulators" IEEE conference on Mechatronics, pages 274-279. 